\title{
Uma análise qualitativa do atendimento à população em situação de rua na cidade de Varginha/MG a partir da perspectiva de gestores: um estudo sobre o Centro Pop
}

\section{A qualitative analysis of the assistance to the homelessness in the city of Varginha/MG from the perspective of managers: a study about the Centro Pop}

\author{
ANA CLARA DA COSTA LIMA SILVA (D) \\ http://orcid.org/ \\ BRUNO EDUARDO FREITAS HONORATO (D) \\ http://orcid.org/0000-0003-3670-0095
}

\section{RESUMO}

O objetivo deste trabalho foi analisar o atendimento à população em situação de rua da cidade de Varginha/MG a partir da perspectiva de gestores da rede pública ligados a essa população. A análise, de natureza qualitativa, foi realizada a partir de categorias construídas a posteriori. Na coleta de dados foram realizadas análise documental e entrevistas semi-estruturadas com quatro gestores envolvidos diretamente com a política pública de atendimento à população em situação de rua de Varginha/MG - em especial tratando do principal equipamento de atendimento essa população na cidade: o Centro Pop de Varginha/MG. Os principais resultados i) reforçam a necessidade de revisão do caráter eminentemente quantitativo e formal da avaliação da política no município e ii) apontam para várias inconsistências operacionais em relação às instruções dos manuais sobre o Serviço Especializado em Abordagem Social e o manual de Orientações Técnicas sobre o Centro Pop.

Palavras-chave: Avaliação de políticas públicas; população em situação de rua; Centro Pop; políticas públicas; políticas sociais. 


\section{Abstract}

The objective of this study was to analyze the attendance to homeless people of the city of Varginha/MG from the perspective of managers of the public service connected to this population. The analysis, of a qualitative nature, was carried out from categories constructed a posteriori. Data collection consisted of documental analysis and semi-structured interviews with four managers directly involved in the public policy of assisting the population living in the Varginha / MG street situation - in particular, dealing with the main service equipment for this population in the city: the Centro Pop from Varginha/MG. The main results (i) reinforce the need to review the predominantly quantitative and formal nature of the policy evaluation in the municipality, and (ii) point to various operational inconsistencies in relation to the manuals on the Serviço Especializado em Abordagem Social and the manual of Orientações Técnicas sobre o Centro Pop. Keywords: Evaluation of public policies; homelessness; Centro Pop; public policy; social policies.

\section{INTRODUÇÃo}

Existe uma dificuldade em administrar as políticas sociais em um país como Brasil, assim como reconhecer e corrigir as disfunções em sua execução. Segundo Costa (2008) as políticas sociais são repletas de desafios por diversas causas, primeiramente por depender de vários organismos, várias instâncias decisórias, que demandam negociações entre diversos agentes e níveis de governo. Um segundo motivo é pela barreira que a burocracia pública acarreta, acompanhado de disputas administrativas e ambições pela liderança em execuções dos programas. E uma última causa é a capacidade institucional e gerencial limitada que o Brasil possui, o que gera uma inconsistência de informações, mecanismos e instrumentos para executar os programas, que possui como consequência uma má atuação de pessoas nos mesmos. Além disso, problemas como a regressividade, o tradicionalismo e o acesso segmentado a tais políticas interferem diretamente na sua efetividade (COHEN; FRANCO, 2013). Avançar no conhecimento técnico, a partir da criação de diagnósticos adequados, avaliação de programas sociais 
e melhorar os sistemas de informação têm sido um grande desafio para aumentar a eficiência do gasto social.

A Constituição Brasileira de 1988 surge com um desenvolvimento na área de proteção social e possui vários avanços que são vistos como igualitários e universalistas, como a instituição do sistema de seguridade social no Brasil, que se organiza em previdência, saúde e assistência social (CUNHA; CUNHA, 2008). Entretanto, por falta de controle ou desconsideração às metodologias de avaliação que acompanham e reorientam os projetos o subsídio estatal não é designado a partir de carências, mas sim a partir do poder de reivindicação, que notoriamente é mais difícil para as pessoas carentes defenderem seus direitos ou interesses nas questões políticas. Nesse sentido, populações vulneráveis como a população em situação de rua carecem de atenção política que permita a distribuição de renda e o reconhecimento de seus direitos como grupo social heterogêneo.

A população em situação de rua tem sido estudada por vários autores de áreas diversas (COSTA, 2005; GHIRARDI; LOPES; BARROS; GALVANI, 2005; FERREIRA; MACHADO, 2007; VARANDA; ADORNO, 2004; MAGNI, 2010; FERREIRA, 2006; FERREIRA, 2010; NEVES, 2010; HONORATO; SARAIVA, 2016; HONORATO; SARAIVA; SILVA, 2017; HONORATO; SARAIVA, 2017). As visões e formas de abordagem teóricas, muitas vezes, são destoantes, embora haja um consenso de que as políticas sociais no Brasil ainda não conseguem estabelecer uma proposta que atenda às reais necessidades dessas pessoas. Neste trabalho, optou-se por uma abordagem aplicada de análise qualitativa da política pública de atendimento à população em situação de rua em um município especifico - Varginha/MG - como fonte de reflexão sobre a efetividade da Política Nacional para População em Situação de Rua em aspectos particulares de sua implementação. Intenta-se, com isso, destacar elementos de relevância funcional/intraorganizacional que refletem diretamente a realidade municipal no tratamento dessa política.

Para tanto, foi realizada uma pesquisa de natureza qualitativa a partir de entrevistas semiestruturadas com 4 gestores ligados a população em situação de rua. Dois deles ligados diretamente ao Centro Pop de Varginha-MG e outros dois ligados ao Abrigo Institucional e à SEHAD (Secretaria de Habitação e Desenvolvimento 
Social). No caso da SEHAD, foi entrevistada a assistente social e no abrigo foi entrevistada a coordenadora. As entrevistas foram analisadas por meio da análise de conteúdo. O objetivo deste trabalho pode ser expresso da seguinte maneira: analisar o atendimento à população em situação de rua da cidade de Varginha/MG a partir da perspectiva de gestores da rede pública ligados a essa população.

Além desta introdução, o artigo apresenta mais quatro seções: a segunda trata-se do referencial teórico, que aborda a população em situação de rua e o Centro Pop; a terceira é composta pelo percurso metodológico do trabalho; a quarta a análise dos dados; e, por fim, as considerações finais.

\section{A população em SituaÇÃo de RuA E os Centro de Referên- cia Especializado para essa população - Centro Pop}

A persistência da ocorrência de indivíduos que residem nas ruas dos grandes centros urbanos faz-se evidente tanto em metrópoles quanto em cidades menores. Desde as sociedades pré-industriais existiam os chamados miseráveis nas ruas e, de acordo com Bursztyn (2003), no começo do século XVII, por haver muitos pobres migrando para os centros das cidades, foram realizadas políticas públicas a fim de consolidar essas pessoas em seus locais de origem. Com o final do sistema servil, não era mais de interesse dos senhores cuidar das classes inferiores, dessa maneira, as pessoas ficaram livres para procurar seu sustento no novo mercado. Com o passar dos anos as diferenças foram aumentando, de acordo com Bursztyn (2003) as pessoas que viviam na classe abaixo do ciclo econômico começaram a ter suas vidas prejudicadas pela falta de moradia e comida, tendo como consequência a dificuldade de conseguirem empregos.

Nos dias de hoje a realidade continua a mesma, o sistema capitalista agrava o número de pessoas em situação de rua e a globalização que gera as novas tecnologias e provocam desempregos. Silva (2006) descreve população em situação de rua como:

Grupo populacional heterogêneo, mas que possui em comum, a pobreza extrema, os vínculos familiares interrompidos ou fragilizados e a inexistência de moradia convencional regular, em função do que as pessoas que o constituem procuram os logradouros públicos (ruas, 
praças, jardins, canteiros, marquises e baixos viadutos), as áreas degradadas (dos prédios abandonados, ruínas, cemitérios e carcaças de veículos) como espaço de moradia e sustento, por contingência temporária ou de forma permanente, podendo utilizar albergues para pernoitar e abrigos, casas de acolhida temporária ou moradias provisórias. (SILVA, 2006, p. 22).

As pessoas em situação de rua sobrevivem através do acesso precário a ferramentas públicas, como por exemplo assistência social, serviços de saúde e também podem receber apoio de entidades filantrópicas ou religiosas. Porém, muitas dessas pessoas são invisíveis aos olhos da sociedade devido ao preconceito ou mesmo pela indiferença, em razão disso podem se tornar perigosos se cometerem algum crime, já que estão expostos a drogas, bebidas alcoólicas, e entre outros, mas a maioria é estigmatizado como risco à segurança pública.

A Política Nacional para a População em Situação de Rua está prevista no Decreto $\mathrm{n}^{\mathrm{0}}$ 7.053/2009 e possui os seguintes princípios além da igualdade e equidade: respeito à dignidade da pessoa humana; direito à convivência familiar e comunitária; valorização e respeito à vida e à cidadania; atendimento humanizado e universalizado; e respeito às condições sociais e diferenças de origem, raça, idade, nacionalidade, gênero, orientação sexual e religiosa, com atenção especial às pessoas com deficiência. E, possui como objetivos os seguintes pontos: assegurar o acesso amplo, simplificado e seguro aos serviços e programas que integram as políticas públicas de saúde, educação, previdência, assistência social, moradia, segurança, cultura, esporte, lazer, trabalho e renda; garantir a formação e capacitação permanente de profissionais e gestores para atuação no desenvolvimento de políticas públicas intersetoriais, transversais e intergovernamentais direcionadas às pessoas em situação de rua; instituir a contagem oficial da população em situação de rua; produzir, sistematizar e disseminar dados e indicadores sociais, econômicos e culturais sobre a rede existente de cobertura de serviços públicos à população em situação de rua; desenvolver ações educativas permanentes que contribuam para a formação de cultura de respeito, ética e solidariedade entre a população em si- 
tuação de rua e os demais grupos sociais, de modo a resguardar a observância aos direitos humanos; incentivar a pesquisa, produção e divulgação de conhecimentos sobre a população em situação de rua, contemplando a diversidade humana em toda a sua amplitude étnico-racial, sexual, de gênero e geracional, nas diversas áreas do conhecimento; implantar centros de defesa dos direitos humanos para a população em situação de rua; incentivar a criação, divulgação e disponibilização de canais de comunicação para o recebimento de denúncias de violência contra a população em situação de rua, bem como de sugestões para o aperfeiçoamento e melhoria das políticas públicas voltadas para este segmento; entre outros.

$\mathrm{O}$ assunto sobre a população em situação de rua possui grande complexidade pois agrega o conjunto de fatores que provocam a ida das pessoas para as ruas. Existe uma trajetória da situação de pobreza para a situação de rua, de acordo com Varanda e Adorno (2004) há inúmeras situações que podem levar as pessoas para as ruas e tudo depende de como elas lidam com cada caso, por isso nada pode ser generalizado. Dentre essas situações existem casos de prostituição, doenças, drogas, bebidas alcoólicas, desemprego, violência em casa.

Entre os exemplos de políticas públicas para as pessoas em situação de rua, que seguem a Política Nacional da População em Situação de Rua, são o Serviço Especializado em Abordagem Social, Centros Temporários de Acolhimento, Centros de Referência Especializados de Assistência Social (CREAS) e o Centro Pop (Centro de Referência Especializado para a População em Situação de Rua).

O Centro de Referência Especializado para a População em Situação de Rua - Centro Pop está previsto no Decreto no 7.053/2009. De acordo com o Ministério do Desenvolvimento Social (2015) o Centro Pop é uma unidade pública orientada para atender a população em situação de rua. Os serviços prestados a essas pessoas abrangem o atendimento e atividades direcionadas para o desenvolvimento de sociabilidades, com o objetivo de fortalecer os vínculos interpessoais e familiares para proporcionar a construção de novos projetos de vida. No Centro POP as pessoas recebem orientação individual e em grupo, procurando possibilitar condições de acolhida na rede socioassistencial, contribuir para novos projetos de vida, colabo- 
rar para restaurar e preservar a integridade e autonomia deles e também promover ações para reinserção familiar e comunitária. Além disso o Centro Pop também deve promover lugares para a guarda de pertences, de higiene pessoal, alimentação e auxiliar na elaboração de documentos. O Centro Pop é um local para crianças, jovens, adultos e idosos, todos aqueles que sobrevivem nas ruas e a utilizam como local de moradia. Ele entra como alternativa de reinserção social, deve proporcionar aprendizado para as pessoas alcançarem autonomia e participação social.

A partir disso, existe o Serviço Especializado em Abordagem Social que consiste em um processo de trabalho planejado de aproximação, e possui como objetivo a construção de um vínculo de confiança com pessoas e famílias em situação de risco pessoal e social nos espaços públicos, no qual eles atendem, acompanham e mediam acesso à rede de proteção social, como por exemplo o Centro POP (BRASIL, 2013). O Serviço Especializado em Abordagem Social conta com a colaboração dessas unidades de oferta de serviço (Centro POP) para a definição de lugares que necessitam de intervenção, que podem ser rodoviárias, semáforos, metrô, prédios abandonados e entre outros, juntos eles realizam um diagnóstico socioterritorial. As principais atividades do Serviço Especializado em Abordagem Social são identificar famílias e indivíduos em situação de risco pessoal e social com direitos violados, a natureza das violações, as condições em que vivem, estratégias de sobrevivência, procedência, projetos de vida e relações estabelecidas com as instituições; construir o processo de saídas das ruas e possibilitar condições de acesso à rede de serviços e a benefícios assistenciais; promover ações de sensibilização para divulgação do trabalho realizado, direitos e necessidades de inclusão social e estabelecimento de parcerias. A necessidade de oferta do Serviço Especializado em Abordagem Social é de responsabilidade do órgão gestor da política de assistência social do município, através do diagnóstico socioterritorial. O controle social da oferta do Serviço Especializado em Abordagem Social é realizado pelos Conselhos de Assistência Social, esses conselhos possuem competência para acompanhar a execução da política de Assistência Social, apreciar e aprovar a proposta orçamentária de acordo com as diretrizes das conferências nacionais, 
estaduais, distrital e municipais, a partir do seu âmbito de atuação. Dessa maneira, cabe ao órgão da Administração Pública responsável pela coordenação da Política de Assistência Social nas três esferas de governo gerir o Fundo de Assistência Social, sob orientação e controle dos respectivos Conselhos de Assistência Social.

Em relação à abordagem das pessoas, existe uma equipe apenas para isso no Centro POP que saem diariamente às ruas. Os profissionais percorrem praças e áreas públicas e particulares onde há registros de pessoas em situação de rua, por isso é de extrema importância a participação dos cidadãos em informar o Centro POP os locais onde verem essas pessoas. A partir dessas denúncias ou abordagens, as equipes localizam essas pessoas e fazem a identificação que é o recolhimento de dados pessoais, onde moram, de onde são, quantos são (em caso de famílias), entre outras informações e, em seguida, é feito o encaminhamento para o Centro POP.

As pessoas em situação de rua não precisam de encaminhamento para serem atendidas no Centro POP, elas podem ir por conta própria. Nesse local os serviços oferecidos são: de saúde, de educação, emissão de documentos, inserção nos programas sociais, de acolhida, fornecimento de alimentos e de roupas e o principal é o contato com a família. Os atendimentos com psicólogos e assistentes sociais visam à superação da rua, a partir de um acompanhamento sistemático e não apenas o fornecimento de benefícios momentâneos.

De acordo com o documento de Orientações Técnicas: Centro de Referência Especializado para População em Situação de Rua Centro Pop (BRASIL, 2011) o Centro POP deve possuir capacidade de atendimento de 80 famílias ou indivíduos por mês, deve possuir um coordenador (a), dois assistentes sociais, dois psicólogos (as), um técnico de nível superior, preferencialmente com formação em Direito, Pedagogia, Antropologia, Sociologia ou Terapia Ocupacional, quatro profissionais de nível superior ou médio para a realização do Serviço Especializado e dois auxiliares administrativos. A cartilha sobre o Centro POP aconselha as pessoas a apoiar as políticas públicas e organizações que trabalham com essa população, não dando esmola, mas sim informando para as unidades onde essas pessoas se encontram a fim de agilizar a abordagem social. O importante 
é realizar também o trabalho de sensibilização com a sociedade, a rua é um espaço público e de acordo com a Constituição Federal e a Declaração Universal dos Direitos Humanos, todas as pessoas possuem o direito de ir e vir, o que não deve acontecer é usar os espaços públicos como moradia.

\section{Percurso Metodológico}

A pesquisa, de natureza qualitativa, teve como técnica de coleta de dados entrevistas semiestruturadas e análise documental. De acordo com Boni e Quaresma (2005), as entrevistas semiestruturadas consistem em questões previamente definidas, tendo como característica uma conversa informal, que o pesquisador possui oportunidade de desenvolver sobre o tema do trabalho. Dessa maneira, as entrevistas foram realizadas com pessoas ligadas ao Centro Pop, a coordenadora e o psicólogo do local, a assistente social da SEHAD (Secretaria de Habitação e Desenvolvimento Social) e a coordenadora da Associação Beneficente Kerygma que é responsável por cuidar do abrigo institucional. Os roteiros das entrevistas foram elaborados a fim de conhecer o trabalho dos respectivos entrevistados, buscando identificar a realidade social descrita pelas pessoas, como sugerem Vieira e Rivera (2012), além de compreender o ponto de vista dessas pessoas sobre o alcance que a população em situação de rua possui aos direitos constitucionais e analisar pontos sobre o funcionamento do Centro Pop, como recursos recebidos, autonomia de decisões, infraestrutura física, quantidade de pessoas atendidas, multidisciplinaridade da equipe, falhas, direitos, e entre outros, e o apoio do governo nesse programa.

A outra técnica de coleta utilizada foi a análise documental que de acordo com Oliveira (2007) dispõe de materiais que ainda não receberam tratamento analítico. Foram analisados manuais do Ministério do Desenvolvimento Social e Combate a fome sobre o Serviço Especializado em Abordagem Social e também o manual de Orientações Técnicas sobre o Centro Pop. 
Quadro1. Legenda dos entrevistados

\begin{tabular}{|l|c|}
\hline \multicolumn{1}{|c|}{ Cargo } & Legenda da Análise \\
\hline Coordenadora do Centro Pop & E1 \\
\hline Referência Técnica - Psicólogo do Centro Pop & E2 \\
\hline Assistente Social da SEHAD & E3 \\
\hline Coordenadora do Abrigo Institucional & E4 \\
\hline
\end{tabular}

Fonte: Elaborado pelos autores.

Os dados coletados foram analisados a partir de uma abordagem de análise de conteúdo, tendo como referência os trabalhos de Franco (2005), Bardin (1979) e Silva e Fossá (2017). Em meio aos procedimentos que podem ser utilizados na análise de conteúdo, escolheu-se para essa pesquisa a análise categorial que, de acordo com Bardin (1979), consiste na fragmentação do texto em várias categorias captando as partes que se assemelham, mas que também se diferenciam. Permitindo que seja realizada uma análise dos sentidos expressos nas falas dos indivíduos.

Dessa maneira, após a transcrição das entrevistas, de acordo com Silva e Fossá (2017), a análise foi organizada em três fases, a primeira é a pré-analise em que acontece a sistematização das ideias iniciais por meio da leitura do material coletado. A segunda fase que consiste na exploração do material para identificar perspectivas de entendimento do texto, em que foram desenvolvidas as categorias a posteriori. A terceira fase representa o tratamento dos resultados, inferências e interpretação na qual buscou-se compreender como se caracteriza o atendimento à população em situação de rua na cidade de Varginha/MG, além de conhecer aspectos sobre o Centro Pop, como: história, planejamento, regras, manutenção, dinâmica dos funcionários, desafios e também características sobre a população de rua de Varginha, suas necessidades, perfis e entre outros, a fim de perceber se o Centro Pop desse município possui o que é primordial para o apropriado atendimento dessa população. 


\section{ANÁLISE DOS DADOS}

\section{Elaboração de relatórios mensais}

Nessa seção, serão analisadas as falas dos atores do Centro Pop de Varginha sobre os relatórios mensais e anuais e a forma de avaliação da política pública pelo governo municipal, em especial do Centro Pop enquanto uma instância dessa política.

"É muito burocrático, a gente tem que mandar todo mês e esse relatório é um relatório assim, já pronto, só pra gente preencher mesmo com os dados e se a gente não preencher isso eles cortam a verba, cortam tudo". (E1).

"A estatística está aí e o que mudou? Estatística não muda nada, o que muda é investimento, recurso público, é a atuação objetiva". (E2).

O Centro Pop necessita entregar a prefeitura relatórios mensais e anuais de atividade e produtividade, além desse também existem os relatórios para o Governo Federal realizado no próprio site do MDS (Ministério de Desenvolvimento Social) que abrangem assuntos como quantas pessoas foram atendidas, números de atendimentos, número de migrantes, se são dependentes químicos e entre outros. Esses relatórios são realizados online, que de acordo com a E3, não funcionam corretamente e estão constantemente travando, isso é um problema que pode desmotivar os funcionários.

Um dos aspectos percebidos na fala do E2 é que os relatórios não são feitos nem interpretados a fim de investigar as limitações e buscar soluções para uma possível melhora, de acordo com ele as estatísticas não ajudam a resolver o problema e não há interesse pelo governo em resolver os problemas dos municípios. Os relatórios são exigidos de forma rigorosa, a fim de terem um controle quantitativo das ações. É importante que os setores realizem essa prestação de contas, pois, caso contrário, a verba não é liberada. Porém, segundo o E2, mesmo com esse controle existe a má distribuição de dinheiro por parte do governo federal, além de não existirem profissionais para desempenhar uma análise desses dados. 
A análise e reformulação dos relatórios implicariam em um maior conhecimento da população em situação de rua da cidade, suas necessidades, quais problemas psicológicos, de saúde e familiares recorrentes, motivos de estarem nas ruas e entre outros, a interpretação desses relatórios permitiria que a prefeitura realizasse melhorias em pontos que fossem necessários fazendo com que essa população seja melhor compreendida e percebida aos olhos de todos.

"Acaba tomando muito mais tempo da gente os preenchimentos de formulários e sistemas, tanto do governo federal e estadual, de quem a gente recebe dinheiro. A gente brinca que assim pra cada 1 real são 5 formulários. (E3)".

De acordo com a E3, os relatórios são imprescindíveis para a organização do trabalho. A E3 acredita que ter um banco de dados é fundamental para novos funcionários, que precisam pesquisar e entender as condições da população em situação de rua da cidade. Porém, os relatórios deveriam melhorar, pois possuem erros que o governo federal não corrige ano após ano, além de levar muito tempo para preencher respostas anualmente que já foram preenchidas mensalmente. Isso implica na credibilidade do site e na importância que o próprio governo federal possui sobre os dados que tanto exigem, já que de acordo com um exemplo da assistente social, já tiveram erros inclusive de saldos. Os sistemas deveriam facilitar alguns trabalhos que são exigidos por burocracia e que no final não possuem necessidade por já terem sido preenchidos todos os meses, a fim de otimizar as tarefas dos funcionários.

“Eu acho útil, mas as vezes por falta de pessoal falta tempo pra você pegar esses dados e fazer um trabalho legal pra população. Precisaria ter tempo de pegar esses dados". (E3).

Entre os relatórios de atividade e produtividade, não existe na cidade de Varginha uma pesquisa que colete a informação sobre quantas pessoas estão em situação de rua na cidade, há uma dificuldade em reunir esses dados pois a população em situação de rua é variável. Alguns vão para outra cidade, outros podem ser 
presos, outros não possuem documentos de identidade e podem ser contados mais de uma vez, entre outros motivos. Não contabilizar a população em situação de rua no Censo traz complicações para destinar recursos orçamentários visto que o número que possuem é apenas estimativo, gerando complexidade em distribuições de dinheiro para atender todas as demandas necessárias. De acordo com a E3 uma coleta de dados poderia ser feita a fim de uma maior organização da demanda. Os dados que o Centro Pop possui sobre a população de rua da cidade de Varginha são das pessoas que eles atendem e das abordagens que tentam realizar nas ruas, e a coleta íntegra dessas informações levaria tempo e seria necessário a contratação de outras pessoas para desenvolver essa atividade pois os funcionários atuais do Centro Pop não possuem disponibilidade visto que dispõem de inúmeras tarefas sendo inviável interrompê-las.

A E3 relatou sobre um avanço do Centro Pop que foi a implantação do PIA (Plano Individualizado de Atendimento), que antigamente não possuíam. O PIA consiste em um projeto individual para cada pessoa que passa pelo Centro Pop, nele são elaborados objetivos e plano de atividades para que ela não vá ao Centro Pop apenas para comer e tomar banho e sim recupere aos poucos sua integridade. Por meio desse plano individualizado as pessoas atendidas no Centro Pop possuem um propósito maior em sua passagem por lá, elas desenvolvem o que desejam para o futuro a partir da definição dos seus objetivos, porém depende muito da pessoa também já que nada é feito contra sua vontade.

Da mesma forma que o Centro Pop o Abrigo Institucional também necessita realizar relatórios mensais e anuais para informar o consumo de alimentos, quantos usuários, se há necessidade de reformas e entre outros.

\section{Atendimento à população em situação de rua da cidade de Varginha na visão dos gestores}

\section{i. Quantidade de colaboradores envolvidos}

Na presente seção, será avaliada a quantidade de funcionários envolvidos nas atividades oferecidas pelo Centro Pop de Varginha, a fim de observar se possuem uma equipe completa para realizar 
todos os afazeres e obrigações. A quantidade de trabalhadores foi comparada ao que é estipulado no item de referência técnica do manual de Orientações Técnicas: Centro de Referência Especializado para População em Situação de Rua - Centro Pop.

"A gente gostaria de ter o assistente social com o psicólogo porque a gente consegue distribuir mais as tarefas, tem outro profissional pra conversar" (E1).

"A gente acaba atendendo mais a demanda da instituição do que a do usuário. Quando você tá na dimensão burocrática você acaba atendendo mais a demanda da instituição, é mais importante eu fazer uma ficha, um relatório, alimentar um sistema. A administração pública é muito amarrada nessas coisas" (E2).

O Centro Pop de Varginha possui 10 funcionários, sendo eles secretária, coordenadora, referência técnica (psicólogo), 2 cozinheiros, 1 faxineira, 1 motorista, 3 orientadores sociais que fazem a abordagem social nas ruas. De acordo com o manual “Orientações Técnicas: Centro de Referência Especializado para População em Situação de Rua - Centro Pop" apesar de deixar claro que a equipe pode ser redimensionada e ampliada quando necessário a partir da demanda por atendimento, serviços ofertados e capacidade de atendimento, fica evidente que a falta de um assistente social e de um psicólogo no Centro Pop de Varginha prejudica o atendimento que eles oferecem a população.

O E2 por ser uma referência técnica possui mais obrigações burocráticas do que de atendimento psicológico propriamente dito, é interessante sua fala em que deixa claro que é mais importante lidar com a demanda da instituição do que com a do usuário. Isso é problemático pois existe maior preocupação em manter o sistema do que em atender as necessidades da pessoa em situação de rua. Preencher relatórios, fazer fichas e tarefas burocráticas tem maior relevância do que acompanhar o usuário e entender suas aflições. Mesmo porque, segundo o E2, os relatórios são exigidos não para serem interpretados, a fim de compreender limitações e sucederem melhoras, e sim para provar que o serviço está sendo realizado. Os 
relatórios não são utilizados na retroalimentação da política, sua função acaba sendo meramente avaliativa focada no controle da política e não no seu planejamento contínuo.

Além disso, a E1 expõe que uma das necessidades que o Centro Pop de Varginha possui e que não tem disponível no município é o CAPS 3 (Centro de Assistência Psicossocial) voltado para a saúde mental para pessoas que necessitam de um leito psiquiátrico, por não possuir esse recurso, não há como ter um acompanhamento psicológico das pessoas, já que são encaminhadas para o hospital, mas não existe o leito.

O Abrigo Institucional possui quatro funcionários, 2 são funcionários pagos pela verba repassada a Associação Kerygma pela prefeitura, ou seja, o Kerygma que contratou, eles fazem um rodízio de horário de forma que o Abrigo é acompanhado 24 horas. O terceiro funcionário é da limpeza e a quarta é a coordenadora. A E4 faz o trabalho de auxiliar em qualquer tarefa diária que apareça, desde assistência a população em situação de rua para irem a médicos até arrecadar doações de alimentos quando não é suficiente o dado pela prefeitura. De acordo com a E4 seu trabalho é muito ligado ao da E1, já que quando o Centro Pop não consegue trazer alguma pessoa para o programa a coordenadora do Abrigo é solicitada para fazer essa mediação a fim de ajudar. Dessa maneira, o serviço ofertado pelo Centro Pop abrange pessoas e ações além do que é prescrito no manual "Orientações Técnicas: Centro de Referência Especializado para População em Situação de Rua - Centro Pop", sendo dependente de ajudas de cidadãos de fora e de programa interligado.

\section{ii. A quantidade de pessoas atendidas}

Nessa seção, será analisada a quantidade de pessoas atendidas no Centro Pop de Varginha e se conseguem atender toda a demanda da cidade, de acordo com o depoimento dos agentes envolvidos.

“Por dia recebemos no mínimo 18 pessoas, máximo de 28, 30 pessoas. Tem alguns que vêm espontâneo, tem outros que vem pelo transporte, pelo abrigo, encaminhamentos... Enfim, é possível lidar com a demanda toda". (E1). 
“Então, criar um órgão, um órgão público que dá conta de trabalhar essa demanda, de atender essa demanda, sim, é possível sim, agora né, aí tem que ver quais são as demandas que esse público apresenta, né porque são várias questões, por exemplo, tem a questão de alimentação, de banho, tem a questão de abrigo, tem a questão de moradia né, algumas pessoas têm a condição de evoluir para condição de moradia própria, por exemplo, mas a gente não tem esse recurso". (E2).

De acordo com a E1, o Centro Pop possui o que é necessário para lidar com a demanda da cidade de Varginha, ela conta que no estabelecimento as pessoas em situação de rua podem lavar suas roupas, tomar banho, fazer refeições, usar computadores com internet, retirar documentos e cadastro no CadÚnico, atividades de pintura e artesanato, o que mostra que em sua visão o trabalho realizado é suficiente e atende as necessidades da pessoa.

Enquanto o E2 enxerga que o problema é mais estrutural, e que o Centro Pop não age na raiz desses problemas, pois diz que oferecer serviços como esses citados não resolvem as dificuldades psicológicas de cada um, e sim só dão uma base para que ele possa viver um dia de cada vez. De acordo com o E2, o Centro Pop de Varginha consegue atender algumas demandas da população, mas não todas, como por exemplo de moradia própria.

A discordância dos profissionais do Centro Pop mostra dois extremos de opinião, o tratamento diário disponibilizado para a população em situação de rua como alimentação, banho, limpeza de roupas e atividades de artesanato são bem oferecidos, mas isso não estimula o indivíduo a uma possível mudança de vida. Pela fala do E2 fica evidente que o PIA (Plano Individualizado de Atendimento) não funciona como a teoria apresenta, pois, os objetivos individuais desenvolvidos, a fim de proporcionar aspirações nas pessoas, não é concretizado. O Centro Pop de Varginha atua nas necessidades básicas de cada um, mas não necessariamente no sentido de estimular a reinserção do indivíduo na sociedade. Prova disso é não possuírem um psicólogo para acompanhamento e mesmo que a referência técnica seja um psicólogo ele só realiza atividades burocráticas. Segundo o E2, ações como ajuda na retirada de documentos, ajuda no pedido de Bolsa Família e entre outros são benéficos para a população em 
situação de rua, porém não geram a mudança interna que um indivíduo nessa situação precisa. O E2 ainda reforça que é necessário oferecer apoio psicológico para que haja fortalecimento mental, e para que possam se reencontrar e enfrentar seus obstáculos.

Como antes do Abrigo Institucional ser na cidade ele era na chamada "Fazendinha" fora da cidade, o espaço era menor e o número de pessoas atendidas também era menor. Depois da instalação na cidade o número aumentou devido a ampliação do local, sendo abrigados por noite cerca de 25 a 30 pessoas, podendo extrapolar um pouco em casos de migrantes, e de final de semana esse número diminui, caindo para 18 a 22. De acordo com a E4, 70\% dos abrigados por noite são do Centro Pop e 30\% são os que a conseguem ser alcançados pela Abordagem Social.

A E4 relata um problema que é a mistura de pessoas em situação de rua que estão sóbrias com as que não estão, de acordo com ela acontece muita confusão pois as pessoas que estão tranquilas e sóbrias precisam lidar com aqueles que causam situações por estarem alterados por bebidas ou drogas sendo necessário algumas vezes chamar a polícia. Dessa maneira conforme a E4 seria necessário uma separação no Abrigo para as pessoas acolhidas, a fim de que elas não sejam incomodadas no tratamento ou influenciadas.

\section{iii. Infraestrutura física}

Nessa seção, buscou-se analisar a infraestrutura física do Centro Pop de acordo com o que foi observado em visitas ao local e também de acordo com o depoimento da coordenadora e psicólogo em comparação com o que é estipulado no manual de Orientações Técnicas: Centro de Referência Especializado para População em Situação de Rua - Centro Pop.

“Tem coisa que em sala do psicólogo não existe, por exemplo, não existe o telefone, não existe arquivo que alguém vá precisar entrar aqui para pegar ficha, não existe impressora que o pessoal de lá precise entrar aqui para tirar xerox..." (E2).

Apesar de ficar claro no manual de orientações técnicas que as etapas de implantação e infraestrutura do Centro Pop devem ser 
flexíveis, a fim de se adaptarem a realidade do local, percebe-se uma deficiência no espaço de Varginha. O Centro Pop de Varginha não apresenta salas separadas para atendimento individual ou em grupo, não há ambiente para acolhimento psicológico a fim de atender cada pessoa individualmente ou em grupo, possuem também um espaço pequeno para convívio, e lugar limitado para as pessoas almoçarem, levando a alguns grupos fazerem suas refeições em uma mesa na sala da coordenadora. Não há sala para estoque, acarretando que pacotes de alimentos, pacotes de pães e entre outros fiquem posicionados na sala da coordenadora e psicólogo, atrapalhando a circulação, aparência e organização dos respectivos lugares. A partir da fala da coordenadora ela apresenta o espaço como suficiente e não deixa evidente as limitações que ele possui, ao contrário do psicólogo que expõe os pertences que são posicionados em sua sala como algo que atrapalha o seu trabalho, já que constantemente os funcionários do Centro Pop precisam entrar em sua sala, não existindo então a devida privacidade que uma sala de atendimento psicológico deveria ter.

A infraestrutura do Centro Pop de Varginha possui secretaria, sala da coordenadora, sala da referência técnica, cozinha, sala de convivência junto com refeitório, banheiro feminino e masculino, lavanderia, armários individualizados e quintal, todos os locais são pequenos. Portanto, a infraestrutura atende alguns itens propostos no manual de Orientações Técnicas: Centro de Referência Especializado para População em Situação de Rua - Centro Pop, mas é desprovido de sala de atendimento individualizado, sala de convívio e refeitório separados e salas para atividades referentes à reunião de equipe e/ou salas administrativas. Não possuir sala de atendimento individualizado prejudica o acolhimento das pessoas, pois a qualquer momento são interrompidos não havendo privacidade e limitando o apoio que pode ser oferecido, já que várias obrigações são realizadas na sala da coordenadora e psicólogo. Além disso, é de grande importância ter um estoque no Centro Pop de Varginha devido ao acúmulo de pacotes de alimentos concentrados na sala da coordenadora e psicólogo. A sala de convívio e refeitório são no mesmo lugar, o que complica o acontecimento de outras atividades caso algumas estejam fazendo refeições. Ademais, o re- 
feitório é pequeno e não comporta todas as pessoas que utilizam o espaço cotidianamente.

Outra questão abordada foi o lugar que o Centro Pop está localizado, considerando o fato de ele ter sido ou não escolhido a partir de estratégias em que facilitaria o acesso para a população em situação de rua.

"Preço em primeiro lugar, a casa mais barata, vizinhança porque nesse caso os vizinhos reclamam do público que frequenta, é mais uma situação de conveniência, muitas vezes não se tem o pensamento logístico e estratégico". (E2).

“Ninguém aceitou alugar na hora que ficou sabendo o que ia funcionar, porque tem que ser um galpão, tem que ser um lugar grande, então os donos de galpão na hora que ficaram sabendo o que ia funcionar não quiseram alugar, então foi meio que o único lugar que aceitou". (E3).

Dessa maneira, é constatado que a localização do Centro Pop de Varginha não foi escolhida visando a abrangência de atendimentos possíveis e não foi realizado um diagnóstico territorial como é relatado nas etapas de implantação do Centro Pop do manual "Orientações Técnicas: Centro de Referência Especializado para População em Situação de Rua - Centro Pop". A partir do que é relatado pelos entrevistados a prefeitura teve dificuldade para conseguir alugar um local adequado pois os donos dos estabelecimentos ao saber qual programa seria realizado ali não consideravam uma boa opção, recusando o aluguel. Além disso lugares com muitos vizinhos tendem a não ter uma boa aceitação também. Isso evidencia que uma parcela da sociedade não deseja conviver com a população em situação de rua.

Durante 10 anos a população em situação de rua era abrigada na "Fazendinha", local fora da cidade improvisado, feito pela Associação Kerygma e que recebia uma ajuda da prefeitura. Com o passar do tempo o número de pessoas atendidas foi aumentando e o lugar ficou indevido para a assistência delas. 
"Então a gente tinha um alojamento lá que comportava 15 pessoas, do outro lado 3 pessoas. Então a gente só podia comportar essas pessoas, só que o numero tava evoluindo, evoluindo, evoluindo... Tinha dia que tinha 30 pessoas e tinha que por colchão no chão, começou a ficar muito precário o local pra instalar". (E4).

A partir daquela situação precária, foi realizada uma denúncia que a vigilância compareceu no Abrigo e foi constatado que o local era indevido para o número de pessoas atendidas lá. Não haviam colchões para todos, muitos levavam cachorros e esses dormiam também no meio das pessoas, tinha confusão para oferecer a comida e entre outros. Dessa maneira a prefeitura foi obrigada a encontrar um local adequado para o Abrigo Institucional na cidade, onde se depararam com o problema de locação já que os proprietários se recusam a alugar casas para esse tipo de programa.

"Fomos arrumar um lugar, não consegui arrumar em nenhum bairro, aí com muito custo eu e o secretario achamos um barracão, porque a casa pra comportar esse numero de pessoas também tava sendo muito difícil. Porque pra você encontrar uma casa grande que comporta 25 pessoas tem que ser em bairro nobre, e nos bairros nobres nem de longe consegue, justamente pelo tipo de trabalho e pessoas que frequentam esse lugar". (E4).

Segundo a E4 eles já possuem inúmeros abaixo assinados para desocuparem o local atual, mesmo se localizando em um bairro afastado, a vizinhança reclama e não aceita nem entende o trabalho oferecido. O lugar comporta 30 pessoas, sendo um galpão com divisórias que repartem os cômodos que são um quarto grande, um refeitório, uma cozinha pequena e 2 banheiros. De acordo com a E4 para o tipo de serviço que eles oferecerem é o suficiente, e também existe uma televisão que fica em um lugar onde todos conseguem ver.

\section{iv. Multidisciplinaridade da equipe}

A respeito da questão da multidisciplinaridade, buscou-se identificar o que é necessário para o funcionamento do Centro Pop de Varginha, e se as atividades são realizadas pelas pessoas corretas sem sobrecarregar os funcionários. 
"Eu tô na coordenação, tô na parte administrativa aqui do Centro Pop, mas não tem essa não... A gente é pau pra toda obra”. (E1).

"A Bethânia é assistente social, mas ela tem a função de coordenadora né. Ai a gente não tem assistente social pra trabalhar com função exclusiva de assistente social". (E2).

Na equipe do Centro Pop não existe assistente social e um psicólogo que não seja referência técnica, sendo necessário a coordenadora e a referência técnica realizarem trabalhos que são de outras funções, o que não condiz com a equipe de referência proposta pelo manual de "Orientações Técnicas: Centro de Referência Especializado para População em Situação de Rua - Centro Pop", cujo deixa claro os funcionários que devem existir. A coordenadora do Centro Pop é assistente social, mas não exerce essa função no local, ela realiza trabalhos administrativos e tarefas que surgem diariamente como acompanhamento das pessoas em situação de rua em médicos, pedidos de documentos, escrita de relatórios e entre outros. O psicólogo como referência técnica possui tarefas burocráticas e não realiza o trabalho de sua profissão. A referência técnica é um cargo importante para a realização de tarefas do Centro Pop, porém a presença de um psicólogo é fundamental para o atendimento psicológico dessas pessoas. Dessa maneira, o Centro Pop de Varginha tem seus atendimentos limitados, pois são muitas tarefas para poucos profissionais.

A coordenadora do Abrigo Institucional é presidente da Associação Kerygma, era professora concursada, mas por questões de saúde foi readaptada para a Assistência Social e nesse momento por já exercer trabalhos de caridade foi designada para ser responsável pela administração do Abrigo Institucional.

\section{v. Recursos financeiros e autonomia para realizar ações}

Nessa seção, constam as questões de recursos financeiros, repasse de verbas e autonomia para realizar ações dentro do Centro Pop de Varginha. 
“Mas assim, na questão de faltar alimentação, faltar as coisas, 'ah não vai ter mais atendimento porque não tem alimento', isso nunca aconteceu, entendeu. As vezes a gente pode ter uma dificuldade com veículo que tá em manutenção, uma coisa assim, mas a gente sempre dá um jeito". (E1).

"Aqui em Varginha até que não tanto, é uma prefeitura que supre, sabe assim? Se você falar, tá faltando arroz, feijão, supre, tem telefone, tem uma impressora sabe? E o arroz com feijão você tem basicamente". (E2).

"Agora no caso do centro pop é pouco mesmo, 13 mil do governo federal, nada do governo estadual..." (E3).

Para o funcionamento das atividades realizadas não há falta de recursos para comidas, itens de higiene e materiais para artesanato. Entretanto, faltam recursos para roupas. A E3 informa que a quantia que recebem do governo federal é de $\mathrm{R} \$ 13.000,00$ por mês e a prefeitura de Varginha completa com $\mathrm{R} \$ 1.500,00$ enviados para a Associação Kerygma que gerencia, ela alega que isso é muito pouco para tudo que precisam realizar, e reclama que não recebem nada do governo estadual. Segundo a E3, o repasse de verbas precisaria ser maior para que conseguissem contratar mais profissionais para o Centro Pop, como por exemplo assistente social e psicólogo.

A E3 quando questionada sobre se a distribuição de recursos é suficiente para atender as necessidades do Centro Pop, alegou que os recursos da prefeitura e governo federal não são suficientes, além do governo estadual não repassar nada a eles.

"A gente ainda tem um problema que a maioria dos dinheiros eles vem assim: 'pode gastar com isso', e as vezes a gente precisaria daquele dinheiro pra gastar com outra coisa, e não pode, ele vem específico que só pode gastar com aquela coisa" (E3).

O dinheiro recebido já vem determinado para quais setores deve atender e não pode ser realocado conforme a necessidade local. Dessa forma, muitas vezes a SEHAD devolveu dinheiro pois o governo 
federal mandou verba para itens que não eram necessários. Essa impossibilidade de recondução do dinheiro origina em um trabalho realizado por todos os programas de assistência social da SEHAD que eles remanejam entre si as verbas de setores que sobram para alguns mas faltam para outros. Além disso, a incapacidade de mover as verbas prejudica na eficiência dos trabalhos oferecidos pelo Centro Pop. É compreensível esse tipo de controle, porém seria interessante estudar aspectos para que seja menos restrito essa questão, a fim de ajudar o alcance das necessidades contidas.

Junto a isso relaciona-se a autonomia para realizar ações dentro do Centro Pop, que de acordo com a E1, possuem liberdade para criar atividades desde que não possuam custos, se demandar apenas a mão-de-obra deles há a autorização. Já o E2 questiona a atitude do governo federal pois não considera que os funcionários possuem autonomia para realizar ações que não estão previstas na Política Nacional e Assistência Social, sendo um problema para atender as demandas particulares da cidade e do Centro Pop de Varginha pois cada cidade tem suas particularidades, sendo interessante que os funcionários possam adequar as atividades ofertadas de acordo com a população que a frequenta.

“Eu acho que já está tudo determinado, eu não acho que exista autonomia não, eu acho que já está tudo pré-determinado, pelo menos eu, Carlos, não tenho, não sinto autonomia de criar, de chegar aqui e falar "ah não vou trabalhar dessa maneira", não tem isso, está tudo lá posto na cartilhinha do governo". (E2).

A E4 relata que precisariam de mais recursos para darem uma instalação melhor no Abrigo Institucional, mas entende que as necessidades das pessoas são diferenciadas e que a prefeitura faz o que pode. Informa que acontece de faltar alimentos não só para o Abrigo, mas para vários programas sociais, principalmente no final de ano. E a mesma reclamação da $\mathrm{E} 3$ se repete na $\mathrm{E} 4$, que relata que a burocracia e a incapacidade de realocar verbas atrapalha a suprir as necessidades e urgências diárias, que muitas vezes a salvação é a redistribuição entre os programas sociais. 
"Não falta por causa dessa parceria que a gente tem, em algum lugar pode ter pouco arroz mas tem muito feijão, aí a betania diz: "o meu feijão não veio", aí a gente arruma pra ela na hora. Então essa troca é o que não deixa faltar. Porque prefeitura é complicado, precisa de licitação, leva 2, 3 meses pra liberar e quando libera, libera tudo de uma vez aí tem que consumir pra não perder". (E4).

O depoimento da E4 entra em choque com o que foi dito pela E1 e pelo E2 que revelaram não ter falta de alimentos no Centro Pop.

\section{Discussão}

Construir políticas sociais para pessoas em situação de rua sempre foi desafiador no Brasil, assunto sobre o qual já nos debruçamos em outras oportunidades e com outros olhares (HONORATO, 2014; HONORATO; SARAIVA, 2016; HONORATO; SARAIVA, 2017; HONORATO; SARAIVA; SILVA, 2017; HONORATO; OLIVEIRA, 2020). A população em situação de rua foi praticamente excluída das políticas brasileiras até a década de noventa. Entretanto a luta pelos direitos dessa população já acontecia há algum tempo, mostrando contornos desde 1950 na cidade de São Paulo (Melo, 2015).

A consolidação das políticas enquanto texto manifesta uma prática discursiva importante para a população em situação de rua, em termos de direitos previstos na constituição brasileira. A criação dos Centros de Referência Especializado para a População em Situação de Rua - Centro Pop previstos no Decreto nº 7.053/2009 é relativamente recente em termos de consolidação da política. Os problemas relacionados à utilização da cidade pelas pessoas em situação de rua e os confrontos com a população domiciliada, colocam a administração pública municipal em uma posição de mediadora, ao mesmo tempo em que se situa como produtora e mantenedora da ordem social também possibilita a ação de agentes engajados na transformação das práticas discursivas relacionadas à população em situação de rua.

Muitos dos problemas analisados nesse trabalho poderiam ser lidos a partir de uma visão reducionista que elenca as prioridades das pessoas em situação de rua às suas necessidades básicas 
de sobrevivência, entretanto, a ideia central na política é de que o Centro Pop promova, não apenas a operacionalização de condições básicas de sobrevivência para essa população, mas alternativas de reinserção social proporcionando aprendizado para essas pessoas alcançarem mais autonomia e participação social.

No Brasil, que é, muitas vezes, considerado o país mais descentralizado do mundo (ARRETCHE, 2009; ABRÚCIO, 2005), a descentralização contribuiu para a formação de estruturas operacionais com forte incentivo à ampliação da atuação dos municípios como executores dos serviços públicos de educação, saúde, assistência social e habitação; de forma que a disparidade entre os municípios na implementação de políticas públicas é persistente e notória (Cavalcante, 2014). Por isso, uma análise intraorganizacional - que leve em conta os problemas internos de tais organizações - colabora com a produção de conhecimento sobre os processos internos de implementação da política em nível municipal, de tal forma que, as inconsistências operacionais em relação às instruções dos manuais sobre o Serviço Especializado em Abordagem Social e o manual de Orientações Técnicas sobre o Centro Pop possam ser pensadas de forma retroativa - enquanto retroalimentação - na política nacional. Da mesma forma, insistimos na necessidade de revisão do caráter eminentemente quantitativo e formal da avaliação da política no município, o que é parte de um monitoramento da efetividade da política pública.

\section{CONSIDERAÇõES FINAIS}

Na presente pesquisa buscou-se compreender a percepção dos gestores ligados a população em situação de rua sobre o atendimento a essa população na cidade de Varginha/MG. Na análise qualitativa, buscou-se ainda comparar os dados obtidos com os manuais do Ministério do Desenvolvimento Social e Combate a fome sobre o Serviço Especializado em Abordagem Social, e também o manual de Orientações Técnicas sobre o Centro Pop.

Na primeira categoria, elaboração de relatórios mensais, foi evidenciado como é realizada a criação dos relatórios anuais e mensais e a opinião dos entrevistados sobre a forma de avaliação da política pública pelo governo. Constatou-se que os relatórios são 
feitos pela internet cujo funcionamento do site é lento, atrasando o trabalho dos funcionários, além de que as perguntas são repetitivas podendo ser simplificadas a fim de poupar o tempo que poderia ser gasto com outra atividade. Além disso, os relatórios não são exigidos para serem interpretados com propósito de investigar as limitações do programa e resolver problemas, são exigidos apenas para controle de verbas. Nesse contexto, os relatórios deveriam ter como finalidade também um retorno para o desenvolvimento da política pública, pois é muito importante um maior conhecimento da população em situação de rua da cidade, suas necessidades, quais problemas psicológicos, de saúde e familiares são recorrentes.

A segunda categoria consiste no atendimento a população em situação de rua da cidade de Varginha na visão dos gestores, dentro da qual deriva-se a quantidade de colaboradores envolvidos, em que no Centro Pop é percebida uma falha na composição de funcionários de acordo com o que é estipulado no manual de Orientações Técnicas: Centro de Referência Especializado para População em Situação de Rua - Centro Pop. As atividades principais concentram na coordenadora e na referência técnica do local, pois não possuem o conjunto de assistente social e psicólogo que é imprescindível para o tratamento da população em situação de rua. Constata-se que existe uma carência de funcionários no Centro Pop de Varginha, que de acordo com o psicólogo nas condições atuais acaba sendo mais importante lidar com a demanda da instituição do que com a do usuário. Os funcionários do Abrigo Institucional são coerentes com a atividade que oferece.

Em relação a quantidade de pessoas atendidas, o Centro Pop consegue atender toda a demanda que eles recebem da cidade, porém seu atendimento é focado em alimentação, refeições, higiene, limpeza de roupas, atividades artesanais, assistência para ir a médicos e retirada de documentos, sendo o acompanhamento com psicólogo e assistente social inexistente, já que o psicólogo ao ir para o cargo de referência técnica não tem mais tempo para fazer o atendimento. O Abrigo Institucional o número de pessoas que suporta, conseguindo realizar sua função adequadamente.

Quanto a infraestrutura física o Centro Pop de Varginha possui uma deficiência de espaço de acordo com o que é estipulado no ma- 
nual de “Orientações Técnicas: Centro de Referência Especializado para População em Situação de Rua - Centro Pop", limitando o atendimento que poderia ser oferecido, além de terem pouca privacidade, local para estocagem de alimentos e outros produtos, e área de convívio para essas pessoas. Porém, devido a dificuldade de conseguir a locação de um lugar adequado para ser o Centro Pop há essa limitação que pode justificar a permanência nesse local que é considerado pequeno para o tipo de trabalho ofertado lá. Realizar um diagnóstico territorial visando encontrar o melhor lugar para ter mais atendimentos possíveis fica difícil com o impedimento da vizinhança, as pessoas não aceitam e colocam empecilhos para a instalação de determinados programas sociais perto de suas casas. O mesmo acontece com o Abrigo Institucional, porém o local atende as necessidades do tanto de pessoas que recebem por noite.

Em relação a multidisciplinaridade da equipe do Centro Pop também não condiz com a estipulada manual de "Orientações Técnicas: Centro de Referência Especializado para População em Situação de Rua - Centro Pop", que não possuem psicólogo, assistente social e auxiliar administrativo.

E, por fim, em relação a recursos financeiros e autonomia para realizar ações, constata-se a insuficiência de recursos que é encaminhado para a SEHAD, que encaminha para os fins do Centro Pop e Abrigo Institucional. Não há a falta de alimentos, pois os programas sociais distribuem entre si em caso de carência, mas fica evidente que as verbas são escassas e que se tivesse um reajuste os atendimentos poderiam ser mais eficazes, podendo ter a contratação dos funcionários que faltam no Centro Pop.

Sendo assim, o trabalho oferecido pelo Centro Pop é de grande ajuda para a população em situação de rua de Varginha que tanto precisa de uma assistência, atendem as necessidades básicas diárias dessas pessoas, causam transformações nas vidas, além de contribuir para uma maior facilidade no acesso de direitos fundamentais. Porém um dos seus principais pontos fracos constitui na falta de assistente social e psicólogo para que haja o fortalecimento mental da população em situação de rua, e a devida reinserção social, no trabalho e com a família, portanto seria interessante a contratação desses dois profissionais. Além disso, melhoras na infraestrutura 
do local ajudariam na estocagem de alimentos, circulação de pessoas, aparência e organização; sendo necessárias também salas de atendimento psicológico individual ou em grupo e uma área de convivência além do refeitório, pois a falta disso prejudica o atendimento das pessoas.

Dessa maneira, também é percebido certa falha vinda do papel do governo nessa política pública, prova disso são os relatórios que fiscalizam apenas os recursos financeiros, não analisando os dados a fim de terem um desenvolvimento de suas atividades, seria importante haver uma maior flexibilidade na realização ações pois cada município possui características diferentes, as necessidades mudam de cidade para cidade. Ademais, os recursos financeiros disponibilizados para os programas sociais que abrangem a população em situação de rua, como Centro Pop e Abrigo Institucional, são pequenos e atingem diretamente o atendimento das pessoas pois implica na falta de funcionários adequados, e para não faltar alimentos existe a realocação dos produtos entre os programas sociais.

É importante que as políticas públicas para a população em situação de rua sejam enxergadas com mais relevância para que não fique apenas para a assistência social a responsabilidade exclusiva de atender essas pessoas.

Sendo assim, também é de extrema importância que haja uma maior conscientização da sociedade, já que eles não são tratados como iguais em dignidade, segurança, trabalho nem quando acompanhados pelo Centro Pop. O preconceito ainda existe da mesma maneira, apenas conseguem por meio do Centro Pop acesso àqueles direitos que não conseguem sozinhos. Por isso, entender a situação dessa parte da população, ter generosidade, sensibilidade e aceitação são características imprescindíveis para o avanço da inserção da população em situação de rua na sociedade como um todo.

Sugere-se, para ampliação do quadro de referência sobre o tema em estudo, que sejam feitas pesquisas comparativas entre os municípios que possam respaldar ou confrontar os resultados encontrados nesse trabalho, considerando que a principal limitação desse trabalho - embora seja também a fonte de suas principais contribuições - se deve ao escopo particularizado - âmbito municipal - empreendido pelos autores. 


\section{REFERÊNCIAS}

ABRUCIO, F. A coordenação federativa no Brasil: a experiência do período FHC e os desafios do governo Lula. Revista de sociologia e política, Curitiba, n. 24, p. 41-67, 2005.

ARRETCHE, M. Estado federativo e políticas sociais: determinantes da descentralização. São Paulo: FAPESP, 2000.

BARDIN, L. Análise de conteúdo. Lisboa: Edições 70, 1979.

BONI, V.; QUARESMA, S. J. Aprendendo a entrevistar: como fazer entrevistas em Ciências Sociais. Em Tese, v. 2, n. 1, p. 68-80, 2005.

BURSZTYN, M. No Meio da Rua - nômades, excluídos e viradores. Rio de Janeiro: Garamond, 2003.

BRASIL. Ministério do Desenvolvimento Social e Combate à Fome - Secretaria Nacional de Assistência Social. Perguntas e respostas: Serviço Especializado em Abordagem Social. Brasília, DF, 2013.

BRASIL. Ministério do Desenvolvimento Social e Combate à Fome - Secretaria Nacional de Renda e Cidadania e Secretaria Nacional de Assistência Social. Orientações Técnicas: Centro de Referência Especializado para População em Situação de Rua - Centro Pop. Brasília, DF, 2011.

CAVALCANTE, P. A implementação municipal das políticas sociais: uma análise espacial. Planejamento e Políticas Públicas, n. 42, 2014.

COHEN, E.; FRANCO, R. Avaliação de Projetos Sociais. 11. ed. Rio de Janeiro: Editora Vozes, 2013.

COSTA, A. P. M. População em situação de rua: contextualização e caracterização. Revista Textos \& Contextos, Porto Alegre, ano IV, n. 4, p. 1-15, dez. 2005.

COSTA, B. L. D. As mudanças na agenda das políticas sociais no Brasil e os desafios da inovação. In: CARVALHO, A. et al. Políticas Públicas. 2. ed. Belo Horizonte: Editora UFMG, 2008, p. 27-57.

CUNHA, E. S. M.; CUNHA, E. da P. Políticas Públicas Sociais. In: CARVALHO, A. et al. Políticas Públicas. 2. ed. Belo Horizonte: Editora UFMG, 2008, p. 11-25.

FRANCO, M. L. P. Análise de conteúdo. 2 ed. Brasília: Liber Livro Editora, 2005.

FERREIRA, F. P. M. População em situação de rua, vidas privadas em espaços públicos: o caso de Belo Horizonte 1998-2005. In: SEMINÁRIO SOBRE A ECONOMIA MINEIRA, XII, 2006, Diamantina. Anais... Diamantina: CEDEPLAR, 2006.

FERREIRA, F. P. M.; MACHADO, S. C. C. Vidas privadas em espaços públicos: os moradores de rua em Belo Horizonte. Serviço Social e Sociedade, São Paulo, v. 29, n. 90, p. 1-20, jun. 2007.

FERREIRA, J. Tratar, cuidar: valores e práticas terapêuticas na assistência humanitária ao sans domicile fixe. Antropolítica, Niterói, n. 29, p. 79-97, 2. sem. 2010.

GHIRARDI, M. I. G.; LOPES, S. R.; BARROS, D. D.; GALVANI, D. Vida na rua e cooperativismo: transitando pela produção de valores. Interface. Comunicação, Saúde e Educação, Botucatu, v. 9, n. 18, p. 601-610, set./dez. 2005. 
HONORATO, B. E. F. Ordem e subversão nas cidades: Um estudo sobre a população em situação de rua de Belo Horizonte (Dissertação de Mestrado). Universidade Federal de Minas Gerais, Belo Horizonte, Brasil, 2014.

HONORATO, B. E. F.; OLIVEIRA, A. C. S. População em situação de rua e COVID-19. Revista de Administração Pública, Rio de Janeiro , v. 54, n. 4, p. 1064-1078, 2020.

HONORATO, B. E. F; SARAIVA, L. A. S. Cidade, População em Situação de Rua e Estudos Organizacionais. Desenvolvimento em Questão, v.14, p.158 - 186, 2016.

HONORATO, B. E. F.; SARAIVA, L. A. S. Quando a Casa é a Marquise, o Albergue, a Rua: discursos e políticas sociais para pessoas em situação de rua em Belo Horizonte. Administração Pública e Gestão Social, v.9, p.244 - 309, 2017.

HONORATO, B. E.; SARAIVA, L. A. S.; SILVA, E. R. da. A construção social da ordem e da subversão nos discursos da (e sobre a) população em situação de rua de Belo Horizonte. Revista Organizações em Contexto (online), v.13, p.339 - 383, 2017.

MAGNI, C. T. Nova pobreza e paradoxos da política de inclusão social francesa: considerações a partir de uma oficina cerâmica no socorro católico. Antropolítica, Niterói, n. 29, p. 37-68, 2. sem. 2010.

Melo, T. H. A. G. População em situação de rua e "direito a ter direitos". Novos debates, 2(1), 198-206, 2015.NEVES, D. P. Habitantes de rua e vicissitudes do trabalho livre. Antropolítica, Niterói, v. 29, p. 99-130, 2. sem. 2010.

OLIVEIRA, D. P. R. Planejamento estratégico: conceitos, metodologia e práticas. 23. ed. São Paulo: Atlas, 2007.

SILVA, M. L. L. Mudanças recentes no mundo do trabalho e o fenômeno população em situação de rua no Brasil 1995-2005, 2006.

SILVA, A. H.; FOSSÁ, M. I. T. Análise de conteúdo: exemplo de aplicação da técnica para análise de dados qualitativos. Dados em Big Data, v. 1, n. 1, p. 23-42, 2017.

VARANDA, W.; ADORNO, R. C. F. Descartáveis urbanos: discutindo a complexidade da população de rua e o desafio para políticas de saúde. Saude soc. [online]. 2004, vol.13, n.1, pp.56-69.

VIEIRA, A. M.; RIVERA, D. P. B. A Hermenêutica no Campo Organizacional: duas possibilidades interpretativistas de pesquisa. Revista Brasileira de Gestão de Negócios, v. 14, n. 44, p. 261-273, 2012.

Recebido em: 28-2-2019

Aprovado em: 29-7-2021

Avaliado pelo sistema double blind review.

Disponível em http://mjs.metodista.br/index.php/roc 